\title{
Students in Rural Schools Have Limited Access to Advanced Mathematics Courses
}

S tudents in rural areas and small towns have less access to higher-level mathematics courses in school than their peers elsewhere. ${ }^{1}$ Approximately one-half of students in rural areas and small towns attend schools that only offer one to three advanced mathematics courses. There are serious educational consequences when students do not have the opportunity to take higher-level mathematics courses. Students who do not take these courses typically score lower on assessment tests, which can restrict their post-secondary educational and occupational opportunities. In addition, limited access to advanced mathematics courses adversely impacts the number of qualified students in science, technology, engineering, and mathematics (STEM) job pipelines.

These discrepancies between urban, suburban, and rural schools are not an idle concern. Fully one in five public school students attends rural schools, and that number is growing. ${ }^{2}$ Furthermore, equitable access to a high-level curriculum is the foundation on which our public education system is based.

\section{Key findings:}

- Nearly 50 percent of students in rural areas and small towns attend schools that only offer one to three advanced mathematics courses.

- Only 10 percent of students in rural schools and small towns have access to seven or more courses in advanced mathematics.

- Suburban and urban schools, on average, offer three to four more courses in advanced mathematics than rural schools.

\section{Access to Advanced Mathematics Courses}

Suburban students and those in larger towns are considerably more likely than rural students to have access to a variety of mathematics courses. Only 15 percent of suburban students, for example, have three or fewer advanced courses from which to choose (see Figure 1). Fifty-eight percent of students in urban schools and 41 percent in suburban and large-town schools can choose from as many as seven or more courses in advanced mathematics. In contrast, only 10 percent of students attending rural schools have this kind of access. On average, students in rural areas and small towns attend schools that offer only four courses in advanced mathematics (see Figure 2). ${ }^{3}$

Figure 1. Percentage of Students in schools OFFERING ADVANCED MATHEMATICS COURSES, BY NUMBER OF COURSES OFFERED AND LOCATION

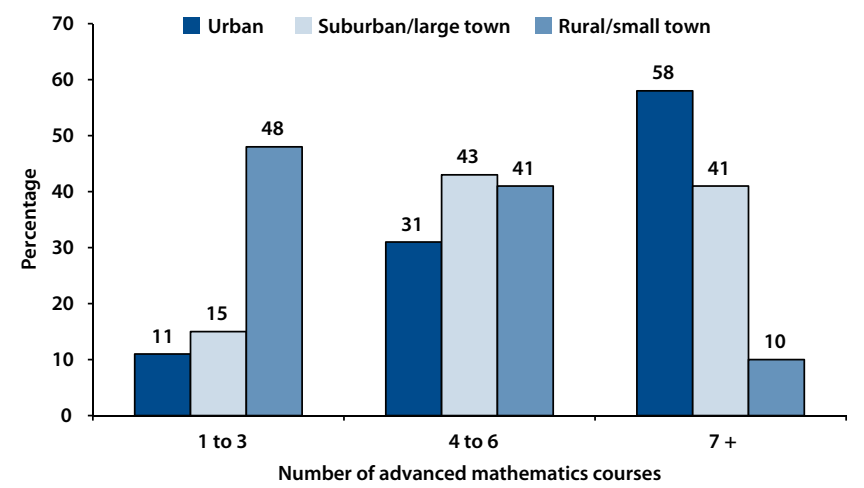

Source: The Condition of Education, 2005. Data drawn from the National Assessment of Education Progress (NAEP) and the High School Transcript Study (HSTS). 
Figure 2. Average number of Advanced mathematICS COURSES OFFERED, BY LOCATION

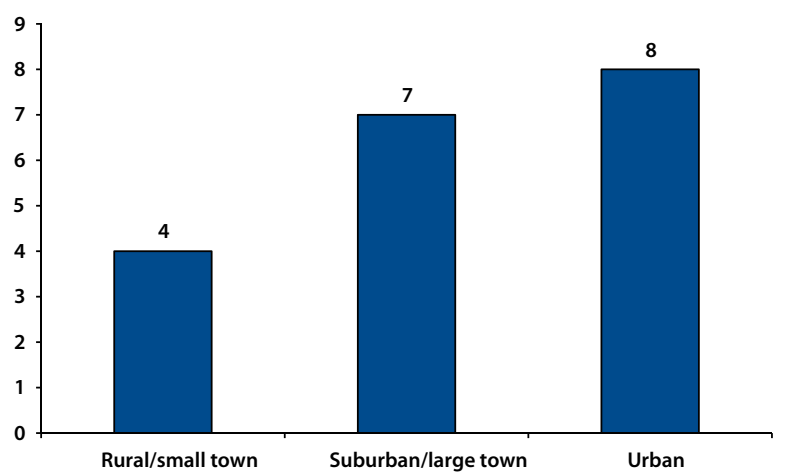

Source: The Condition of Education, 2005. Data used includes National Assessment of Education Progress (NAEP) and the High School Transcript Study (HSTS)

\section{The Consequences of Limited Access to Advanced Mathematics}

Although not all students need to take advanced mathematics courses, potentially millions of students in rural areas and small towns would take advanced mathematics if given the opportunity. Limited access to high-level mathematics courses caps the possible mathematics achievement levels for many rural students and may have other unintended consequences.

Figure 3 presents average mathematics scores on the standardized 2005 National Assessment of Education Progress (NAEP) for twelfth-grade students, as a function of the highest-level mathematics course taken during high school. Students who completed only the bare minimum mathematics for high school graduation, which in many states is algebra I or lower, had an average score of only 117 points out of a possible 300 . For students who took higher-level mathematics courses, the average score was nearly ten points higher for geometry and twenty-five points for trigonom-

Figure 3. Average tWELfTh-grade mathematics NAEP SCORES, BY HIGHEST LEVEL OF MATHEMATICS COMPLETED

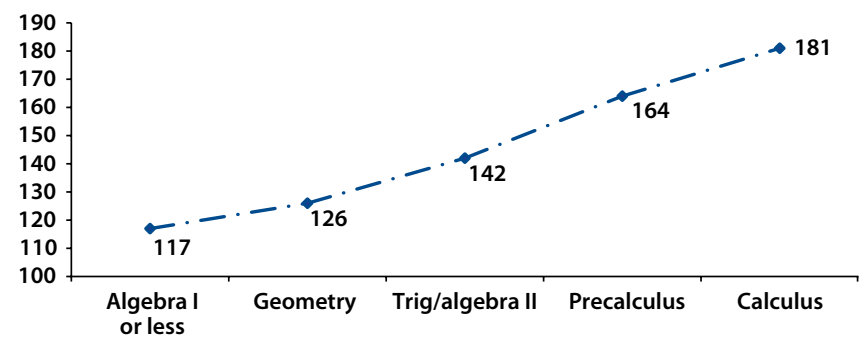

etry or algebra II. Students who took pre-calculus averaged approximately 50 percent higher than students who took the minimum mathematics, and those taking calculus had substantially higher mathematics scores than students who took any less-advanced high school mathematics course.

Taking advanced mathematics is related to other important educational outcomes. Such students are often on a mathematics "pipeline" to major in mathematics-related fields in college, pursue advanced degrees in these areas, and later focus on STEM occupations. Educators and policy makers have for decades been interested in encouraging and supporting students' interests in STEM college majors and careers. The lack of access to advanced mathematics courses facing students from rural areas and small towns limits their opportunities to major in mathematics-related fields in college and subsequently embark on STEM careers.

\section{Factors that Characterize Schools Offering More Advanced Courses}

Not all schools in rural areas and small towns have limited course offerings in advanced mathematics. In general, larger schools tend to offer more advanced courses. For example, schools with 450 or more twelfth-grade students, on average, offer approximately twice the number of advanced courses as schools with fewer than 150 twelfth graders (eight versus four courses).

School size alone, however, is not the only factor impacting the number of advanced mathematics courses offered. Many small schools, after all, either offer advanced mathematics courses or have devised creative solutions, such as distance education. Likewise, just because a school is large does not mean that it offers advanced mathematics courses. For example, when small rural schools are consolidated into large regional schools, the promises of curriculum improvement frequently go unmet. Therefore, we cannot focus solely on school size when asking why rural schools offer fewer advanced mathematics courses than schools in urban and suburban locations.

Other characteristics that likely impact the number and type of advanced mathematics courses include community wealth, location, educational levels and expectations of parents in the communities, and teacher qualifications, to name a few. Little education research has focused specifically on understanding these critical questions about context and its impact on the opportunities that rural students have to enroll in advanced mathematics. As the nation prepares to reauthorize the Elementary and Secondary Education Act, it is important for policy makers to have sound information about what opportunities rural schools are offering students who have the potential to be part of the next generation of mathematicians and engineers.

Source: NAEP, 2005 Mathematics Assessment, accessed using NAEP Data Explorer 


\section{EN D N O TES}

1. This fact sheet employs definitions of region used by the National Center for Education Statistics. Revised in 2006 to be consistent with census categories, geographical regions are classified as urbanized areas, urban clusters, or rural. Urbanized areas and urban clusters are defined as densely settled areas with adjacent densely settled surrounding areas. Urbanized areas have populations of 50,000 or more and contain both a principal city and the suburbs outside the principal city. Large towns or suburban areas are defined as urban clusters containing populations of 25,000 to 50,000 . Rural areas are those regions outside urbanized areas and urban clusters. See http://nces.ed.gov/pubs2007/ruraled/ measuring.asp for further details.

2. For the recent increase in rural schools, see J. Johnson and M. Strange, "Why Rural Matters 2007: The Realities of Rural Education Growth." Arlington, VA: Rural School and Community Trust, 2007.

3. Course offerings are also limited for subjects other than mathematics. Only 53 percent of schools in rural areas offer advanced placement courses in any subject compared with 72 percent in small towns, 85 percent in suburbs, and 78 percent in cities.

\section{REFERENCES}

McArdle, E. "Boon, not Boondock." Editorial. Magazine of the Harvard Graduate School of Education, vol. 52, no. 1 (2008): 16-21.

National Center for Education Statistics. 2005. “The Condition of Education." Washington, DC: U.S. Department of Education.

National Center for Education Statistics. 2007. "Status of Education in Rural America." Washington, DC: U.S. Department of Education.

Oakes, J. "Opportunities, Achievement, and Choice: Women and Minority Students in Science and Mathematics." In Review of Research in Education, edited by Courtney B. Cazden. Washington, DC: American Educational Research Association, 1990.

\section{A C K N OW L E D G M E N T S}

The author would like to thank Mil Duncan, Sally Ward, Todd DeMitchell, Rachel Tompkins, and Kai Schafft for their thoughtful comments and suggestions; Barbara Ray for editorial assistance; and Terri Rippett for guidance throughout the process.

\section{ABOUT THE AUTHOR}

Suzanne E. Graham is an assistant professor in the Department of Education at the University of New Hampshire. (suzanne.graham@unh.edu) 


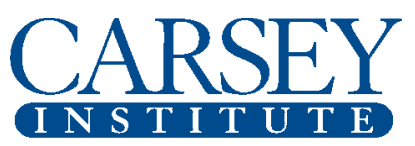

Building knowledge for families and communities

The Carsey Institute conducts policy research on vulnerable children, youth, and families and on sustainable community development. We give policy makers and practitioners timely, independent resources to effect change in their communities.

This work was supported by the Annie E. Casey Foundation's initiative to strengthen rural families and the W. K. Kellogg Foundation.

Huddleston Hall

73 Main Street

Durham, NH 03824

(603) 862-2821

www.carseyinstitute.unh.edu 